\title{
Métodos a Serem Empregados no Treinamento
}

\section{Francisco Gomes de Matos}

As modernas técnicas e práticas de Treinamento de Empregados, que visam à melhor adaptação dêstes às normas de trabalho eficiente, estão meticulosamente estudadas no artigo em aprêço. Seu autor, Francisco Gomes de Matos, estréia assim nesta Revista, apresentando, verdadeira aula a respeito do assunto. - (NOTA DA REDAÇÃO).

treinamento deve representar, para os instruendos, uma "resposta" a seus problemas de trabalho. Só uma aprendizagem dinâmica, que interprete e solucione dificuldades funcionais, pode criar adequada motivação para o treinamento dos empregados.

$E^{\prime}$ natural que haja, inicialmente, certa resistência por parte de alguns servidores. Há aquêles que se julgam auto-suficientes; outros que temem expor-se, desabituados que estão de uma ambiência escolar. E' preciso, portanto, como condição primeira, criar predisposições favoráveis no espirito dos empregados a serem treinados. Informação prévia dos objetivos do treinamento constitui a providência inicial; as prumeiras reuniões devem ser destinadas, exclusivamente, à ambientação.

Mas, a condição essencial para o êxito de um programa de treinamento reside na acertada aplicação dos métodos. Outra condição é fazer com que o empregado compreenda a utilidade dos ensinamentos que lhe são ministrados. Assim a programação do treinamento deve ser precedida por uma análise ocupacional, que orientará o levantamento das necessidades de aperfeiçoamento. O estudo dos conteúdos profissionais, necessários ao exercício do cargo, é condição imprescindivel para instruir a aprendizagem a determinar os métodos específicos para as possiveis deficiências técnicas. 
O treinamento é essencialmente um processo dinâmico. Os métodos tradicionais de ensino, à base de memorização e exposições, exclusivamente orais (palestras, conferências, leituras, etc.), são, via de regra, pouco eficientes. O treinamento é um autêntico instrumento de trabalho. E, um meio objetivo de ajuda técnica aos empregados para obterem eficiência na execução de suas tarefas.

Assim, repetimos, é fundamental que os servidores sintam, de modo indiscutivel, as vantagens do aperfeiçoamento e os seus efeitos no processo de trabalho.

Sob o ponto de vista psicológico, devem-se evitar as situações meramente escolares; substituir o têrmo "aula" pelo têrmo "reun:ão", e "professor" por "coordenador" ou "instrutor". Dêsse modo, o treinamento deve-se realizar através do emprêgo das técnicas de discussão em grupo, em que haja franca participação dos treinandos.

Vejamos algumas dessas técnicas:

\section{REUINIÃO LIDERADA}

E' usada, apenas, para grupos que possuem experiências ou conhecimentos especializados sôbre o assunto em pauta. Visa provocar uma discussão ampla de todos os interessados, com vistas à obtenção de soluções que interpretem o pensamento da maioria.

O Instrutor propõe o tema e faz uma ligeirissima introdução ao debate, apenas com o intuito de motivar o início à discussão.

O êxito, nesse tipo de reunião, depende grandemente do Instrutor no coordenar e disciplinar os debates, evitando dispersão, absorção da palavra por um participante e atritos. Muito do sucesso do Instrutor dependerá do uso adequado de perguntas (ver. "Uso Adequado de Perguntas pelo Instrutor").

O Instrutor deverá ir registrando no quadro as idéias principais, com vistas a facilitar a fixação e a recapitulação quando necessária.

O Instrutor procurará sempre conduzir o"grupo a conclusões fazendo resumos, para que possa, ao vencer o tempo previsto para a reunião, encerrar os debates com uma conclusão final.

Êsse tipo de reunião não é aconselhável para grupos que necessitam de informações básicas (novatos, pessoal mal qualificado, etc.). 
O Instrutor deve esclarecer o grupo sôbre:

- sua função de coordenador,

- o direito à participação que todos possuem,

- a rigorosa obediência ao assunto em discussão,

- que as comunicações e apartes devem ser concisos e e claros,

- que não deve haver colóquios, nem discussões marginais.

\section{MÉTODOS DE DISCUSSÃO}

Temos procurado enfatizar a eficiência da metodologia ativa através de Reuniões Lideradas, Demonstrações Práticas e Dramatizações - sôbre o ensino tradicional, caracterizado por aulas formais, com a mínima participação dos treinandos.

O treinamento - é forçoso repetir - é ensino intensivo; objetiva resultados imediatos.

$\mathrm{Na}$ Reunião Liderada, sob a coordenação de Instrutor, especialmente treinado em conduzir reuniões, a participação dos instruendos é incentivada ao máximo.

Tratando-se de reunião em que a discussão é o instrumento principal, vejamos quais são os seus principais métodos:

Seminário - Grupo de pessoas atualizadas no tratamento de determinado assunto, sob a direção de um lider com habilidade para encaminhar discussões. Objetiva colhêr conclusões com base nas sugestões e críticas apresentadas pelos participantes. O método de discussão - seminário - é indicado para o caso de especialistas no assunto, pois diferença de níveis de conhecimentos entre os componentes pode comprometer o êxito da reunião, desviando-a de suas finalidades.

Painel - Reunião limitada, de 5 a 10 especialistas sôbre o assunto em pauta, sob liderança de pessoa altamente versada na matéria. O tema é especializado, daí usar -se para desenvolvê-lo o tipo de conversação. Após determinado tempo, o presidente faz um resumo dos principais aspectos abordados, visando tirar conclusões práticas.

Simpósio - E' o tipo de reunião para estudos de deter minado problema em que cada participante expõe seu ponto-devista de maneira informativa, sem intenção de debate. No simpósio, cada participante deverá ocupar-se de determinado setor ou aspecto do problema focalizado, apresentando, geralmente, contribuição escrita. O Simpósio é aconselhado para problemas complexos que envolvem vários aspectos que devem ser desen- 
volvidos, para uma compreensão geral do assunto. Enquanto o seminário se caracteriza pela controvérsia, no simpósio, a rigor, não há debate.

Forum - Caracteriza-se pela ampla participação de todos os componentes. Em geral, é feita a exposição do assunto por um dos membros, seguida pelo livre pronunciamento dos participantes. A direção dos trabalhos tem por fim apenas disciplinar as discussões, sem intervir no mérito das mesmas.

Debate - Um orador discorre sôbre o objetivo da discussão após o que o assunto é entregue aos debatedores. Enquanto no forum a participação é ampla, no debate está limitada àqueles especialmente convidados e, sòmente em caso excepcional, é dada a palavra a membros do auditório.

Mesa-Redonda - Alguns autores a definem como "uma associação de simpósio e forum". Há inteira liberdade de pronunciamento, além de ser facultada a participação do auditório nos assuntos discutidos pelos membros da mesa. E' também denominada circulo de estudos.

\section{LEITURA DIR!GIDA}

O método de Leitura Dirigida pade ser deselvolvido através de dois processos:

1. Processo: Leitura Dirigida, com discussão - debates

E' um método através do qual se pode obter resultados proveitosos, desde que o Instrutor cuide em motivar o grupo, a fim de que não se incorra em seu principal inconveniente: a monotonia.

Se o Instrutor não souber empregar recursos de motivação, a leitura não significará para o instruendo além de uma arenga desinteressante.

Procedendo a leitura de livros técnicas ou manuais especificos de treinamento, o Instrutor, além das interrupções normais para explicações e comentários, deve torná-la um instrumento para provocar debates. Ela deve ser, em si, material para discussão. Só assim será eficiente como método de treinamento.

Como atividade suplementar, é interessante, sempre que a emprêsa possuir biblioteca especializada, instituir-se um Ciube de Leitura. Os empregados sob regime de treinamento, ou quaisquer outros de acôrdo com os critérios que se adotem, são orientados na escolha dos livros e dos capitulos que devem merecer maior atenção. Findo o prazo para a leitura, devem apresentar um breve comentário a respeito, que deve ser objeto de discussão em grupo. 
Instruções Metodológicas que devem ser observadas:

a) O Instrutor prepara, com antecedência, o material que deverá ser objeto de leitura coletiva e debates.

b) O documento de trabalho é o instrumento de teorização dos assuntos a serem discutidos. Será lido, em voz alta (ora pelo lider, ora pelos participantes), sendo interrompido, pelo lider, em determinados pontos, para discussão.

c) A discussão será coordenada pelo lider, que concederá a palavra para comentários, sugestões, críticas, observações, contribuições sôbre exper:ências, etc., que se coadunem com a matéria exposta no momento.

d) O participante que estiver com a palavra poderá permitir o aparte, cabendo ao lider disciplinar a discussão, no caso de os debates serem tumultuados.

e) O líder, para evitar que haja monopólio da palavra por algum participante ou digressões fora do tema em pauta, intervirá para restabelecer a ordem, baseado no principio de que o grupo é consítuído de participantes e não de assistentes.

As intervenções do grupo devem ser concisas e objetivas, de modo a que se possa chegar a conclusões.

2. Processo: Leitura Dirigida, com discussão - painel Compreende 4 etapas:

a) Leitura silenciosa: $\mathrm{O}$ coordenador distribui um texto para leitura silenciosa pelo grupo. O participante faz tôdas as anotações que julgue oportunas, de critica ou de reforçamento das idéias.

b) Questionários: E' feita a distribuição, aos participantes, de um questionário sôbre o texto.

c) Divisão em subgrupos: Os participantes são distribuidos em subgrupos, para debates sôbre o texto e respostas aos quesitos do questionário.

d) Reunião Final: $\mathrm{O}$ coordenador promove uma reunião geral para análise dos questionários dos subgrupos e conclusões finais.

\section{DISCUSSÃO DE CASOS E PROBLEMAS}

A discussão de casos e problemas (Case Methods) é usada $\mathrm{cm}$ larga escala pelas universidades americanas. Constituem, mesmo, em alguns casos, o principal método de estudo. Aqui, entre nós, processs. por exceléncia, usado pela Escola de Administraşão de Emprêsas, da Fundação Getúlio Vargas de São Paulo, cujos resultados são de molde a indicar seu emprêgo. 
Um caso é proposto ao grupo com todos os elementos esclarecidos, abstendo-se, todavia, o Instrutor de qualquer julgamento, findo o qual os participantes são convidados a um exame mais aprofundado do problema a fim de apresentarem, na reunião seguinte, as soluções cabíveis. O Instrutor orienta-os sôbre o roteiro a seguir, indica-lhes bibliografia e demais fontes de informação a serem usadas. As soluções apresentadas constituirão o material de discussão.

De outro modo, o desenvolvimento do método pode processar-se através das seguintes fases:

1'a) O Instrutor propõe o "caso", oferecendo tôdas as in formações possive's.

2:) O grupo faz as perguntas que julgar necessárias, para melhor esclarecimento.

3a) O grupo é informado sôbre os recursos de que poderá lançar mão para maior entendimento do assunto (bibliografia, fontes de infurmação, visitas, estágios, etc.

4.) O grupo é dividido em subgrupos, cada um escolhendo o seu lider, que, por seu turno, distribui as responsabilidades de cada um.

5a) Os subgrupos, através de seus lideres, apresentam, na reunião final, as conclusões a que chegaram.

6a) O Instrutor, após conduzir a discussão sôbre as soluções propostas, procura, com a ajuda do grupo. sintetizá-las, ajustando-as à solıção final do caso.

Os "casos" devem envolver complexidades crescentes.

O "caso" força a que o treinando se defronte com "fatos" e não com "idéias", que podem ser recebidas com as resistências ou as acomodações a preconceitos consolidados.

Êste método é excelente para o treinamento de executivos, pois alarga o senso de objetividades no tratamento de problemas comuns a administração.

\section{DRAMATIZAÇÃO}

A dramatização é, também, recurso de alto significado. Essa técnica basea-se nos princípios do psicodrama e sociodrama de Moreno. A encenação de situações é totalmente espontânea, de molde a ensejar um retrato, o mais fiel possível, da problemática, com as implicações que lhe emprestem cada participante.

A dramatização pode ser realizada para reconstituir uma determinada situação, servindo de ilustração aos comentários do Instrutor. Neste caso, não há discussão. Todavia, como técnica 
de treinamento, surte mais efeito quando é usada para motivar debates. Neste caso, sua representação pode ser programada ou espontânea.

E' programada ou teatralizada, quando a situação encenada segue rigorosamente o roteiro traçado. Logo após, o Instrutor conduz a discussão.

E' espontânea quando o Instrutor apenas oferece os dados principais do problema, sendo o enrêdo e os diólogos improvisados pelos participantes.

Há outro tipo de dramatização espontânea, em que o Instrutor apenas propõe o problema. Os intérpretes reunem-se, ràpidamente, em local diferente, e acertam os detalhes principais da orientação a seguir.

A escolha dos intérpretes é feita, sempre, à base de voluntariado.

Após sua realização, o Instrutor pode conduzir o debate, através de discussão livre ou dividir o grupo em subgrupos, que discutirão o assunto em $1^{\text {a }}$ etapa, sendo a conclusão apresentada, depois, pelos seus representantes, ao grupo todo. (Ver: "O treinamento será a solução?" - Exemplo de um caso-dramatização).

\section{INSTRUÇÃO INDIVIDUAL}

A instrução individual é recomendável para as tarefas complexas e para treinar responsabilidades. E' indicado quando se pretende corrigir hábitos viciosos de trabalho e atitudes incorretas evitando as correções em público, sempre constrangedoras e quase sempre ineficazes. No caso de explicar mudança de métodos de trabalho, justificar medidas administrativas que influam no andamento normal do serviço que atinja isoladamente a uma unidade ou departamento. A entrevista individual com o chefe deve ser providência in cial. O chefe instruído sôbre as medidas reunirá, então, seu pessoal para as comunicações necessárias.

A instrução individual é, ainda, recomendável para o adestramento de operários especializados em operações em máquinas, montagens, etc.

\section{INSTRUÇÃO POR ESCRITO}

Constitui providência útil na fixação de pontos importantes que não devem ser esquecidos. Normas regulamentares e princípios que devem ser seguidos freqüentemente devem ser distribuídos, por escrito, aos interessados, para consulta sempre que necessário. 
À instrução por escrito, devem associar - se outros métodos de discussão em grupo, para motivar o conhecimento da matéria, pois a simples entrega pode incorrer no risco de ser guardado sem ser lido. A discussão tem ainda por mérito valorizar pontos importantes que precisam ser fixados e podem passar despercebidos. Igual risco correm os quadros de avisos cujas observações por escrito podem cair na rotina, sem que ninguém preste mais atenção a suas recomendações. Ao chefe cabe, periòdicamente, satravés de encontros formais ou informais, "relembrar" aspectos importantes referentes a regulamentos e normas gerais de serviço.

\section{PRELEÇÃO}

As preleções ou palestras são usadas para acrescentar argumentos novos, como fundamentação teórica e recurso de reforçamento de técnicas empregadas. A preleção do presidente da emprêsa, de um técnico ou palestras periódicas do chefe podem ser de grande significado na fixação de pontos-chaves da politica empresarial. Além do mais, as palestras podem ensejar a qua as pessoas desenvolvam idéias e adquiram 0 gôsto por um aperfeicoamento sistematizado.

A preleção, palestra ou conferência em geral, constitui peça inteiriça, sem interrupção. Após a preleção, conforme a orientação, poderá haver perguntas ao expositor ou debates.

Quando se tratar de uma autoridade no assunto, em geral contra-indica-se debates, tolerando-se, apenas, perguntas. Nestes casos, a palestra possui, tão sòmente, sentido de aperfeiçoamento.

Conforme o público, a conferência oferece sérias dificuldades ao expositor. Quando o auditório é heterogêneo, não estando preparado para o assunto, difícil torna-se o aprofundamento da matéria estudada, forçando o conferencista a manter - se no plano das generalidades.

Quando a conferência se destina a um grupo especializado ou clientela de um curso, o método de preleções é bastante útil, possibilitando a técnicos renomados exporem suas experiências. Um ciclo de palestras, para público selecionado, favorecendo um rodizio de especialistas na matéria, desenvolvendo facetas de um mesmo problema ou de problemas afins, representa excelente motivação para um estudo mais acurado dos assuntos. Para melhor fixação dos conteúdos é interessante associar a conferência ao método de debates ou de explicações posteriores. No primeiro caso a palestra serviria como material de discussão, coordenada pelo conferencista. No segundo caso, após a palestra, o expositor responde às perguntas feitas pelo auditório. 
Para obviar o problema da dispersão nas reuniões para público não selecionado, os conferencistas costumam empregar recursos de fixação, como filmes, slides, cartazes, etc. e, em alguns casos, até dramatizações.

\section{TREINAMENTO NO PRÓPRIO IOCAL DE TRABALHO}

O treinamento no próprio local de trabalho (Funcional) é normalmente usado em situações individuais, mormente no caso de empregado recém-admitido. E' especialmente realizado através de praticagem supervisionada. O empregado é imediatamente colucado em situação de trabalho, sob a orientação do Chefe ou Instrutor especialmente designado, executando tôdas as tarefas peculiares a sua ocupação. E' o método de "aprender fazendo" (in job training). Para algumas tarefas, de pequena complexidade, êste método, pcr si só, preenche suas finalidades instrucionais, embora um treinamento em Relações Humanas seja imprescindivel, para ambientação e integração do empregado na emprêsa.

No comércio, por exemplo, o treinamento funcional é bastante usado, tanto individual, como coletivamente, na instrução e praticagem de vendedores nos princípios fundamentais da Técnica de Vendas.

Este treinamento, realizado principalmente à base de dramatizações de situações de trabalho, torna-se eficiente se na própria ambiência em que operam os empregados. Dêsse modo, pode-se imprimir maior realidade aos problemas simulados.

A finalidade principal do treinamento em serviço consiste no pronto ajustamento do empregado às suas tarefas, para o imediato exercicio profissional. O empregado passa imediatamente a ocupar seu papel no quadro operacional. E' preciso considerar, todavia, o perigo de a instrução do novato ser conduzida por alguém que não possua condições de Instrutor. Nem sempre o servidor mais eficiente é o mais indicado para exercer esta função. Sua eficiência é muitas vêzes conseqüência de habilidade própria, do desenvolvimento de uma aptidão específica e não resultado da aplicação de processos racionais de execução. Em tal circunstância, o aprendiz corre o risco de adquirir práticas defeituosas, hábitos inadequados e vícios de execução difíceis de serem corrigidos posteriormente. E' preciso verificar se o Empregado-Instrutor possui a paciência e as condições didáticas necessárias para ministrar a aprendizagem. Há alguns que são exageradamente ciosos de sua capacidade e perícia profissional desenvolvendo um sentimento esgoista que os inibe de transmitir a experiência adqui- 
rida. Geralmente são autodidatas que adotam por diretriz o lema: "Êles que aprendam como eu, dando duro". Quando um dêsses é escolhido para Instrutor e não se sente a vontade para recusar, pois trata-se de escolha de seu superier hierárquico, aceita, mas sem se dedicar ao aprendiz como deveria, além de não lhe ensinar "tudo o que sabe"... Assim, a indicação daqueles considerados formalmente pela gerência como sendo os melhores instrutores, por serem os mais produtivos, pode significar: fator de desajustainento funcional. Esta situação é bem mais frequiente do que se julga à primerra vista. Dai ser necessário cuidado especial na escolha dos Instrutores. Adiante examinaremos melhor êste problema.

Quando o trabalho é mais de ação, de aplicação motora, constitui técnica eficiente a Demonstração. O Instrutor mostra como se executa uma tarefa, finda a qual o aprendiz, sob a super. visão do mestre, tenta reproduzir a experiência. Nestes caso, revela-se de grande eficiência a sistemática usada pelo método TWI (Training Within Industry), largamente empregado no treinamento de operários pela sua objetividade. Senão vejamos:

COMO ENSINAR UM TRABALHO

Ponto I - Prepare o Aprendiz.

Ponha-o à vontade.

Indique o trabalho e verifique o que o aprendiz já sabe a respeito dêle.

Desperte no aprendiz o interêsse de aprender o trabalho.

Coloque o aprendiz em posição correta.

Ponto II - Apresente o Trabalho.

Fale, mostre e ilustre uma fase importante de cada vez.

Insista em cada um dos pontos-chave.

Ensine clara, completa e pacientemente, não ensinando mais do que aquilo que o aprendiz possa aprender.

Ponto III - Faça o Aprendiz Executar o" Trabalho.

Peça ao aprendiz para fazer o trabalho.

Faça-o explicar cada ponto-chave à medida que êle fôr executando o trabalho. Corrija os erros no momento.

Por meio de perguntas, vá verificando se êle compreendeu. Prossiga até ter certeza de que o aprendiz sabe. 
Ponto IV - Acompanhe o Progresso do Aprendiz.

Encoraje o aprendiz a tomar êsse trabalho. Anime-o a fazer perguntas. Diga-lhe a quem deve procurar quando precisar de auxilio. Verifique o trabalho dêle. Vá, gradualmente, deixando que o aprendiz trabalhe por si mesmo, sem a sua interferência.

\section{ENTREVIST $\Lambda$}

Outro método usado para treinamento individual em serviço é o da Entrevista com o chefe imediato ou um técnico especializado. Os chefes empregam grandemente êste recurso para instruir seus subordinados. A entrevista que deve ser conduzida em um clima de informalidade deve obedecer à técnica a fim de alcançar os objetivos definidos, evitando dispersão e perda de tempo. Na entrevista, o chefe deverá motivar o empregado a que exponha sem constrangimento suas opiniões, devendo ouvir mais que falar, de modo a poder formar juizo acêrca do nivel intelectual e capacidade técnica do empregado. A entrevista poderá constituir, assim, uma verificação das necessidades de treinamento e o primeiro passo para a sistematização de um programa de aperfeiçoamento.

A Entrevista, todavia, é, em si mesma, um processo de treinamento. Na fase de ambientação é, através da entrevista, que o chefe instrui o novato sôbre o regulamento, normas de serviço e politica institucional. É, ainda, reunindo seus auxiliares, quer individualmente, quer em grupos, que o chefe explica as ordens de serviço e instrui sôbre os variados aspectos do trabalho realizado sob sua supervisão.

E' axiomático que qualquer programa de treinamento deve considerar fundamentalmente os objetivos que envolve o conhecimento do campo de trabalho sôbre o qual a instrução deve ser ministrada e o nível dos instruendos. Assim, quando se trata de treinar, no próprio local de trabalho, um empregado para função técnica é òbvio que a metodologia tem que ser diferente. Um dos métodos usados, preferencialmente, nestes casos - é o $E_{s \text { - }}$ tágio.

\section{ESTÁGIO}

E' a permanência supervisionada do empregado ou candidato a emprêgo, em um cargo ou função, com a finalidade de treinamento das técnicas e práticas que lhes são especificas. 
O estágio envolve, geralmente, as seguintes fases:

a) Instrução Inicial.

b) Observação.

c) Leitura Dirigida.

d) Coleta de Material.

e) Elaboração de Pareceres e Relatórios.

O estagiário inicialmente recebe instruções pormenorizadas. sôbre suas responsabilidades funcionais e a rotina de serviço. Observa seus colegas trabalhando e anota tôdas as ponderações a respeito dos métodos de execução. Entrega-se, então, ao estagiário uma bibliografia especializada sôbre o seu trabalho, orientando-o acêrca dos aspectos de maior importância. Na leitura dos trabalhos o estagiário deverá anotar alguns tópicos para discussão posterior. Algumas emprêsas adotam, com grande proveito, $\mathrm{Ma}$ nuais de Instrução, para leitura dirigida e debates. Completada a fase de leitura, o estagiário reune todo o material necessário para início de suas atividades. Como fase complementar, para verificação da eficiência do estagiário, ou mesmo como fase de aplicação do processo de treinamento - que como atividade pedagógica é um processo contínuo - oferece-se, aos estagiários, oportunidades de estudo de situações e problemas de trabalho, solicitando-lhes a elaboração de pareceres técnicos a respeito. Outrossim, pede-se aos estagiários que façam um relatório preciso sôbre o estágio realizado. O estágio é, muitas vêzes, um processo de seleção. Muitos empregados só são admitidos depois de concluirem satisfatòriamente o estágio. Daí usar-se a expressão estágio probatório, para especificar o período experimental do empregado, na emprêsa, para efeito de admissão.

\section{RODízIo}

Consiste em estágios parcelados do empregado pelos várias. seções e setores de trabalho de um departamento ou, ainda, pelos. demais departamentos da emprêsa, objetivando possibilitar ao. estagiário uma visão de conjunto dos serviços e como se processam suas inter-relações.

0 rodizio é aconselhado principalmente para os cargos de supervisão e chefia. Seria interessante, também, que todos os. responsáveis pelo treinamento do pessoal fôssem submetidos prèviamente a um processo de rodizio por todos os setores da emprêsa a fim de que com conhecimenio de campo possa melhor orientar e executar os programas de treinamento.

Na emprêsa bancária, por exemplo, em que as atividades são, em grande parte, realizadas à base de rotinas simples, o estágio. revela-se o método mais eficiente de treinamento. 


\section{ESTUDO DE DOCUMENTAÇÃO E PESQUISA}

É o método de treinamento em serviço pelo qual o empregado procede a uma pesquisa nos arquivos, colhendo material, para estudo. São casos e problemas já solucionados e que se prestam para fins de treinamento. O empregado revê a problemática e a solução apresentada, procurando, êle próprio, fazer um julgamento a respeito. O estudo da documentação arquivada, com finalidade crítica, é um dos métodos de grande eficiência usados no treinamento funcional de novatos, principalmente para cargos técnicos.

Como já nos referimos anteriormente, o treinamento funcional, isto é, no próprio local de trabalho, possui sempre caráter intensivo; objetiva a preparação rápida do empregado para o imediato exercício profissional. O treinamento, porém, é uma atividade contínua. Não deve limitar-se a uma programação formal e rigida. E' um processo eminentemente flexível e informal, baseado na verificação das necessidades de aperfeiçoamento. Estas, quando levantadas, justificam a programação de um processo de treinamento mais sistemático que se realiza extrafuncionalmente, em um setor especializado da emprêsa: o Departamento de Treinamento.

\section{CINE FORUM}

E' recurso valioso para a motivação da aprendizagem. Realiza-se através de um filme que é projetado como instrumento para provocar comentários e trocas de impressões.

Para atingir as finalidades do Cine Forum, deverá o filme apresentar de modo interessante as diversas fases e os variados problemas atinentes às atividades ocupacionais explorando o triplo aspecto técnico-psicológico-social. Dêsse modo o desenvolvimento bem conduzido de uma história ou de uma variedade de situações provocará comentários por parte de técnicos incumbidos da apresentação do filme e, mesmo, admitirá discussão pelos assistentes.

Prevê-se para melhor execução dessa diretriz uma exposição paralela em que os diversos aspectos focalizados pelo filme mereçam tratamento teórico e sirvam de ponto de partida para os comentários do professor de debates dos alunos.

Garantir-se-á a multiplicação das oportunidades didáticas imprimindo-se tal seqüência ao filme que, em determinados momentos, se criem problemas a serem discutidos, interrompendo-se quando oportuno a projeção para a realização do debate. 


\section{ESTÁGIOS EM OUTRAS EMPRÊSAS OU SERVIÇOS}

Várias são as oportunidades em que uma emprêsa necessita que uns mais de seus servidores se aperfeiçoem em uma ocupação ou se adestrem em uma tarefa, sem condições de realizar êsse treinamento na própria estrutura empresarial. Dêsse modo, entra em contato com outras organizações que oferecem boas possibiliclades de aprendizagem nas ocupações ou tarefas em causa, com o fito de promover programas de estágio. Os estagiários ficam tha emprêsa em regime de "internos", a tempo integral, ou durante algumas horas do expediente normal de trabalho.

O estágio abre perspectivas amplas, representando preciosa experiência de situações novas, de técnicas de execução mais avançadas e observações várias sôbre métodos de trabalho, cujas aplicações, em sua emprêsa, poderão contribuir para melhor rendimento funcional e maior produtividade.

O estágio é um método universalmente usado. As Universidades Americanas e a rigor todos os "Colleges" europeus usam-no como complementação prática do ensino teórico. Os alunos, em determinada fase do curso, revesam-se em um programa EscolaTrabalho. Esta prática trouxe resultados altamente vantajosos, o que justifica sua ampla divulgação. Como decorrência, vários cursos de treinamento, de menor duração e com caracteres mais intensivos, foram instituídos dentro do mesmo regime EscolaEmprêsa. Estas iniciativas celebrizaram-se pela denominação de "Sandwich Courses".

Em contrapartida, as emprêsas, também, podem assumir o compromisso de instituirem ou fazer com que instituições técnico. pedagógicas criem cursos do tipo "sandwich", com uma ordenação diferente da anterior: Trabalho-Escola. Caberia à escola oferecer a fundamentação técnica e científica do trabalho realizado por um determinado grupo profissional. Haveria, assim, perfeita articulação entre as tarefas executadas pelos empregados e as atividades didáticas no curso programado.

\section{VISITAS E VIAGENS DE ESTUDO}

Método muito usado e de resultados bastante compensadores, além de ser de fácil execução e pouco oneroso, quando na miesma área geográfica da emprêsa, são as visitas a estabelecimentos análogos, com fins de observação e estudo.

A visita, todavia, para constituir método de treinamento deve ser programada com antecedència, precedida por uma reunião de instrução, onde serão fixados, pelo Instrutor, os pontos principais 
que devem merecer atenção durante a visita. Igualmente, após a realização da mesma, o instrutor deve reunir o grupo - que foi assessorado na visita por um especialista da emprêsa - e discutir informalmente os variados aspectos do trabalho que foi dado observar.

$A_{S}$ viagens de Estudo, por seu turno, quer seja para visita de observação, realização de estágio ou freqüência e participação em cursos ou congressos possui uma particularidade, de ordem psicológica, que as torna método, diferente, dada sua boa receptividade pelo empregado. A escolha do servidor - ao contrário da resistência passiva que pode suscitar em outros casos, como já examinamos - deve revestir-se de um sentido de prêmio, o que é altamente motivador.

Como em tôdas as atividades de treinamento há que se cuidar atentamente do Acompanhamento e Verificação dos Resultados, sem o que a atividade poderá ser desvirtuada. Temos visto como uma viagem de estudo se transforma em puro "turismo", por falta de planejamento, supervisão e contrôle.

\section{CURSOS EM ESCOLAS PROFISSIONAIS}

Constitui método dos mais freqüentes o envio de empregados a escolas de formação e treinamento para participarem de cursos profissionais.

Embora sendo atividades externa, não dispensa que haja uma forma mixta de acompanhamento e complementação na emprêsa, através de reuniões de instrução suplementar e verificação da aprendizagem. E' interessante que o chefe acompanhe e verifique periòdicamente as atividades escolares de seus subordinados com o objetivo de estimulá-los a um constante aprimoramento.

\section{PARTICIPAÇÃO EM CONFERÊNCIAS, CONGRESSOS, \\ MESA-REDONDA, ETC.}

É um excelente processo de aperfeiçoamento, possuindo, como as viagens de estudo, significado de prêmio e distinção especial a escolha para participar das reuniões.

E' um método usado, evidentemente, para funções técnicas, exigindo, muitas vêzes, apresentação de trabalho, o que enriquece as oportunidades de aprendizagem.

As reuniões, de acôrdo com o método de discussão usado, equivalem a verdadeiros cursos de treinamento. 
DISCUSSÃO DE RELATÓRIOS E TRABALHOS PRÁTICOS

Êste é um método de treinamento que se associa com atividades extra-organizacionais: estágios, visitas de estudo, pesquisas, etc.

Os treinandos são divididos em grupos para executarem uma determinada tarefa, finda a qual relatam ao grupo o resultado de stias experiências. Êste relatório é objetivo de discussão, coordesiada pelo Instrutor. 